\title{
NON-INVASIVE MOISTURE MONITORING WITHIN AN EARTH EMBANKMENT - A PRECURSOR TO FAILURE
}

\author{
P.D. Jackson*, KJ Northmore*, PI Meldrum*, DA Gunn*, J. Wambura**, B. Wangusi**, J.R. Hallam* \\ \& G. Ogutu** \\ * British Geological Survey, Kingsley Dunham Centre, Keyworth, Nottingham, NG12 5GG \\ ** Ministry of Public Works and Housing Materials Testing \& Research Dept, Nairobi, Kenya
}

KEYWORDS: Embankment, Slope Failure, Geophysics, Non-invasive, Moisture Monitoring

NDT\&E Conference, Railway Engineering-2000, Commonwealth Institute, London, 5-6 ${ }^{\text {th }}$ July, 2000

\begin{abstract}
An experimental monitoring system is described using electrical resistivity as a proxy for imaging changing moisture content distribution in engineered earthworks. The approach is illustrated using a case history concerning a road embankment constructed of tropical red soil in western Kenya. Tropical red soils have highly variable properties, governed by their soil fabric and mineralogy. As earthworks materials, their geotechnical behaviour is extremely sensitive to changes in moisture content and compaction. The relationship between moisture content and electrical resistivity was established in the laboratory on core obtained using a monitored drilling and sampling technique. The non-invasive nature of electrical resistivity surveys was exploited in the design of a monitoring system placed below the pavement in the topmost layers of compacted soil. Monitoring over a period of 18 months is reported, starting prior to the construction of the pavement following the completion of soil compaction. Initially substantial variability in moisture content was inferred from surface monitoring, and even larger changes were seen in corresponding downhole measurements. The moisture content within the body of the embankment stabilised after 6 months, while a moist layer 'trapped' beneath the pavement dissipated over the following 10 months. Two surveys were undertaken during the 'December rains'; they showed large changes in moisture content had occurred quickly in the surface layers on one side of the embankment. This area subsequently failed as a small landslip and was remediated by additional drainage.
\end{abstract}

\section{INTRODUCTION}

The moisture content of soil controls both its density and strength making it the key property when considering the stability of embankments containing soils. Earthworks are used for embankments / cuttings carrying road and rail links and there are many examples where they have been used as dams, particularly overseas. Increased water content increases the likelihood of a sliding failure because soils will be heavier, and shear strength reduces as pore pressures increase.

Non-invasive geophysical methods have potential to monitor moisture content. Electrical resistivity, for example, is sensitive to the moisture within a soil. In the field, resistivity tomography utilises arrays of simple metal stakes as electrodes in schemes that enable the measurements of electrical resistance to be inverted into the electrical resistivity of the sub-surface in two and three dimensions [1,2,3,4]. Being a 
remote method, such resistivity surveys do not require the use of boreholes, which themselves may disturb the moisture distribution.

The electrical resistivity of soils and porous rocks is controlled by:

- Density / Porosity

- Saturation

- Pore-fluid resistivity

- Matrix resistivity

- Pore-space morphology.

In order to use electrical resistivity as a proxy for moisture content it is necessary to establish a relationship that applies to the embankment concerned. The use of electrical resistivity to assess the water content of fully and partially saturated reservoir rocks has been established more than half a century in the oil industry [5]. More recently, the method has seen use in characterising soils [6,7,8,9]. If matrix conduction is small, such as in saturated sands, the original results of Archie [5] are applicable and provide an initial model from which to predict the effects of changing moisture content. For clay-rich soils, matrix conduction is a significant process and no generalised model exists, for such cases empirical laboratory relationships may be necessary.

This general approach of assessing ground properties can be summarised as follows:

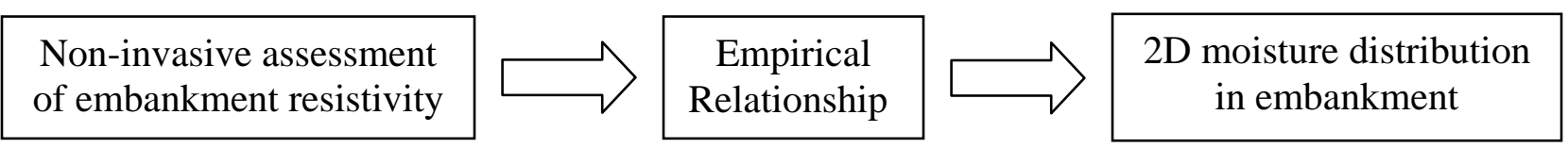

This approach is illustrated using an example of research carried out on a tropical red-soil road embankment in western Kenya, as part of a research programme for the Department for International Development Development [10].

\section{TROPICAL RED SOIL EMBANKMENT (KENYA)}

Tropical red clay soils contain iron and aluminium oxides (which impart their red coloration), have distinctive clay mineralogies and are characterised by a porous soil fabric comprising 'bonded' aggregations, or clusters, of clay particles and finely disseminated iron oxide. In their natural state they are relatively free draining and even in areas of high rainfall tend to be only partly saturated. They also tend to posses relatively high field strengths resulting from bonding of the aggregated soil particles and the effect of soil suctions arising from their partially saturated condition. Red soil road embankments often suffer severe vertical and lateral deformations, most notably evidenced by severe longitudinal cracking in the road pavements which develops close to the embankment shoulders as the soil materials respond to moisture variations over successive wet and dry seasons (Figure 1).

Compacted field density and moisture content of the fills during construction are known to contribute to the causes and extent of embankment distress, as are moisture movement and redistribution within the embankment fills. In many instances, on existing road embankments, vertical and horizontal deformation measurements have been made and related to periods of rainfall but with no attempt to measure variations in moisture conditions within the embankment material itself. In experimental or trial embankments, some attempts have been made to relate deformations to measured moisture contents [11]. 
An embankment on the Molo-Olenguruone route was selected (Figure 2) and subsequently drilled to collect undisturbed samples [12] and instrumented for resistivity tomography surveys. Being predominantly clays, the compacted soils in the embankment allow matrix conduction. Consequently, representative 'undisturbed' samples of the red clay embankment materials were obtained so that controlled experiments could be carried out in the laboratory to determine the variation in resistivity with changing moisture content. To preserve the core, it was encased immediately in a plastic liner whose ends were sealed with airtight, plastic caps.

The laboratory measurement technique is shown in Figure 3 where the whole of the core can be seen to be passing electric current uniformly in the axial direction, with measurements made over $50 \mathrm{~mm}$ sections at $50 \mathrm{~mm}$ intervals [13]. Thus the measurements characterise the whole of the core and can be related directly to the whole-round sub-samples taken for the measurement of moisture content and bulk density. We experimented with smaller sub-samples but found they were often affected by subsequent disturbance and were hence regarded as being less representative than the larger whole-round ones. The cross plot of resistivity and moisture content in Figure 4 displays a consistent relationship that was subsequently used to relate non-invasive assessments of embankment resistivity to moisture content enabling moisture variations within the embankment to be monitored.

Resistivity measurements were also undertaken on the uncased borehole wall using the electrode array shown in Figure 5, the electrodes being forced against the borehole wall using a pneumatically operated piston. The results of these measurements are compared with the corresponding ones made on the core in Figure 6. Fine scale variability can be seen in both data sets, with the laboratory values showing far greater changes. The generally lower values observed in the borehole are consistent with higher temperatures downhole (e.g. 20 deg C) compared to the laboratory (11.5 deg C). The higher variability of the laboratory values could be due to the fact that the electric current is constrained to flow uniformly in the core, while downhole it is highly variable (see Figure 5). The downhole values were affected by a greater depth interval than the separation of the potential electrodes ( $\Delta \mathrm{V}$ in Figure 5 ).

\section{RESISTIVITY SURVEYS}

Resistivity data was acquired by means of a line of 40 electrodes, with a spacing of $1 \mathrm{~m}$, deployed across the embankment, with electrode contacts located at $500 \mathrm{~mm}$ depth below the road pavement. A major advantage of this technique is that subsurface measurements can be made without the need for numerous access holes bored through the embankment fill, which itself can lead to modification of the natural pattern of moisture movement within the embankment materials. Each line of electrodes records data over a 'volume slice' approximately equivalent to a 2 metre wide section across the whole embankment width to its full depth. The resistivity data can thus be presented as a cross-sectional resistivity 'map'. Successive measurements at selected intervals enable a sequence of resistivity images to be obtained which can be interpreted in terms of moisture movement patterns over time.

While published examples demonstrate that 2D and 3D inversions of resistivity measurements can identify the shape of subsurface structures, they can be unrealistic in their reconstruction of resistivity values. For example noise-free numerical experiments are seen where the reconstructed values of resistivity are in error by over $100 \%[2,14,15]$. Consequently, we have applied a simple correction, the Barnes layer method [16], to the construction of pseudosections using pole-dipole measurements (equivalent to a Schlumberger array where the current sink at B is removed to 'infinity', as shown in Figure 7). Referring to Figure 7, in essence, the method assumes that values of apparent resistivity apply to the region between the potential electrodes $(\Delta V)$ to a depth equal to $A B / 3$. Taking the shallowest 
apparent resistivity as being true, the deeper values are corrected from the top down by considering them as equivalent resistors in parallel. For the two-layer case, when the distance between the source of current (I) and the measuring point $(\Delta \mathrm{V})$ is at least 8 - 10 times the thickness of the topmost layer, the corrected resistivities are close to those of the deeper layer (see the results in Figure 7). The agreement is 2-3\% for the conductive overburden unlike the apparent resistivities. Consequently, we believe this technique has merit as a means of converting the upper parts of standard apparent resistivity pseudo-sections to resistivities [17] and have adopted it for processing the resistivity measurements made on the embankment. To assess the changes in resistivity deep within the embankment the analysis presented here would need to be supplemented by inversion processing as described above.

The topography of the embankment will induce artefacts in such resistivity pseudo-sections as illustrated in the upper diagram in Figure 8. Here a 3D numerical resistivity model [18], simulating the geometry of the embankment, has been used to calculate resistivity measurements for processing into a resistivity pseudo-section as described above. This response, characteristic of the embankment shape, has been used to correct subsequent resistivity pseudo-sections as shown for completeness in the lower diagram. The embankment monitoring process, from measurement to resistivity-pseudo-section was tested using a numerical simulation. The simulated embankment, shown in the upper diagram in Figure 9, contains a near surface zone of higher resistivity (250 ohm-m) representing a drier region within the overall embankment (100 ohm-m). The resistivity pseudo-section, in the lower diagram, reconstructs the resistivity value of the anomalous zone to within $10 \%$ of their true values while deeper values directly below the zone have greater errors (50-60\%). We took these errors to be acceptable because they are similar to the spread seen in the laboratory data used to construct the empirical resistivity-moisture content relationship.

Installation of the electrode monitoring system occurred in April 1993 with data acquired immediately after installation. Some of the data in these first measurement sets were observed to have a greater noise level than other comparable ones within the same data set. The characteristics of these measurements are typical of poor electrical contact between the metal electrodes and the soil (i.e. high electrical contact resistance). However, the electrical contact improved after the embankment was surfaced with asphalt. The resistivity pseudo-sections, corrected as described above, are shown in Figure 10. The pseudosections themselves were interpreted in terms of moisture contents by applying the laboratory determined resistivity / moisture content relationship shown in Figure 4.

\section{EMBANKMENT MONITORING}

The corrected moisture content sections are shown in Figure 11 where the values of moisture contents near the surface of the embankment can be seen to have varied substantially over the 18 month monitoring period. The dataset for April 1993 has lower moisture contents (higher resistivities) in some of the central regions that we have attributed to electrode contacts being initially poor. This is partly due to the ground about each electrode being disturbed during installation and not having sufficient time to recover. An increase in moisture content can be seen in the topmost $2.5 \mathrm{~m}$ from April 1993 to Dec $1993 \mathrm{a}$. There was significant rainfall during this period and the asphalt top layer was added in November. Subsequently, after the pavement had been laid, the moisture content of this topmost soil-layer reduced gradually. Substantial changes in moisture content also occurred on the RHS of the embankment over the depth interval 4-8 metres. Field observations identified a seepage horizon had developed close to this level. Its drainage over the embankment's right shoulder is the likely cause of the high moisture contents in the 4-8 m depth interval, (as seen on the Dec 93b section in Figure 11). 
These high apparent moisture contents delineated on the RHS of the embankment are consistent, both temporally and spatially, with the landslide observed on Dec 15th 1993, as shown in Figure 12. It would appear that water exited from a seepage horizon at 2-3 $\mathrm{m}$ and ran down the side of the embankment causing the soil saturation to increase with a corresponding loss of strength, eventually resulting in a landslip. After the landslide, gravel drains were installed to combat the build up of moisture in this area. The sections in Figure 11 post dating the slip (Dec 93b) indicate that the embankment responded favourably with reduced moisture contents in the affected depth interval, returning to their September 1993 values. The zone of higher moisture content (B in Figure 11) persisted in the right shoulder after the asphalt pavement was laid in November 1993, while the central portion beneath the pavement dried back.

\section{CONCLUSIONS}

Non-invasive geophysical surveys can detect changes in resistivity within embankments that can, in turn, be related to moisture content once applicable relationships between these two properties have been constructed. Being non-invasive, automatic and using simple metal electrodes, resistivity surveying is ideal for embankment monitoring applications.

Understanding how moisture moves through embankments and engineered soils will improve assessments of standard construction methods and the imaging technique provides a rapid aid to determining the optimum location and design of remedial measures.

Moisture content being the only seasonal control of resistivity, monitoring changes in electrical resistivity with time enables subtle changes in moisture to be extracted from complex background values. Consequently, this method can be used as early warning of anomalous build up of moisture (e.g. heavy rains) once the seasonal cycle has been monitored and new earthworks stabilised. This technique is also applicable to earthworks in general both overseas and in the UK. It may also be applied to monitoring moisture content changes in natural and engineered earth slopes or pre-existing landslides. As such it has significant potential in providing early warning of seasonal (e.g. rain induced) first-time slope movements or reactivation of existing landslides.

\section{ACKNOWLEDGEMENTS}

This work is published with the permission of the Director BGS (NERC). The case-study was supported by the Department for International Development and the Ministry of Public Works and Housing (Kenya).

\section{REFERENCES}

${ }^{1}$ Constable, S. C., R. L. Parker and C. G. Constable. 1987. Occam's inversion - a practical algorithm for generating smooth models from electromagnetic sounding data. Geophysics 52 : 289-300.

${ }^{2}$ Sasaki, Y. 1992. Resolution of resistivity tomography inferred from numerical simulation. Geophysical Prospecting 40 : 453-463.

${ }^{3}$ Sasaki, Y. 1994. 3D resistivity inversion using the finite element method. Geophysics 59 (11): 453-463.

${ }^{4}$ Loke, M. H. and R. D. Barker. 1996a. Practical techniques for 3D resistivity surveys and data inversion. Geophysical Prospecting 44 (3): 499-523 
${ }^{5}$ Archie, G.E., 1942. The electrical resistivity $\log$ as an aid in determining some reservoir characteristics, J. Petroleum Tech., 5:1-8.

${ }^{6}$ Mualem Y, Friedman S P, 1991. Theoretical prediction of electrical conductivity in saturated and unsaturated soil. Water Resources Research, 27, No. 10, 2771-2777.

${ }^{7}$ Rhoads J D, Ratts A C, Prather R J, 1976. Effects of liquid phase electrical conductivity, water content and surface conductivity on bulk soil electrical conductivity, Soil Sci. Soc. Am. J., 40, 651-655.

${ }^{8}$ Jackson, P.D., Taylor Smith D., \& Stanford P.N., 1978. Resistivity-porosity- particle shape relationships for marine sands: Geophysics, Vol. 43, No. 6, pp. 1250-1268.

${ }^{9}$ Jackson P D, Ogilvy R D, Flint R C, and Meldrum P I, 1995. Areal mapping of water content within surface sediments by electrical resistivity, Sellafield, Cumbria. British Geological Survey Technical Report WN/95/33C (Issue 1.0).

${ }^{10}$ Northmore K.J.N. and Jackson P.D., 1994. Tropical roads: preventing embankment collapse. Earthworks, Issue 7 Nov 1994, British Geological Survey, Keyworth Nottingham.

${ }^{11}$ Dagg. M and K Russam, 1966. The relation between soil shrinkage and the development of surface cracks in an experimental road in Kenya. Road Research Laboratory, Ministry of Transport, RRL Report No. 12, 25 pp.

${ }^{12}$ Hallam, J.R. and K.J. Northmore, 1993. Geotechnical borehole sampling of tropical red clay soil. British Geological Survey Technical Report, WN/93/27, 85 pp.

${ }^{13}$ Jizba, Z.V., Campbell, W.C. and T.W. Todd, 1964. Core resistivity porfiles and their bearing on dipmeter survey interpretation. Bulletin of the American Association of Petroleum Geologists, Vol. 48, No. 11 (November, 1964) pp. 1804-1809.

${ }^{14}$ Loke, M.H. and R.D. Barker. 1996b. Rapid least-squares inversion of apparent resistivity pseudosections by a quasi-Newton method. Geophysical Prospecting 44 : 131-152.

${ }^{15}$ Olayinka, A. I. and U. Yaramanci. 2000. Assessment of the reliability of 2D inversion of apparent resistivity data. Geophysical Prospecting 48 (2) : 293-316.

${ }^{16 a}$ Barnes, H.E., 1952. Soil investigation employing a new method of layer-value determination for earth resistivity interpretation. Highway Res. Board Bull. 65, 26-36.

${ }^{16}$ Telford, W.M., Geldhart, L.P., Sheriff, R.E. and D.A. Keys, 1976. Applied Geophysics, Cambridge University Press, London, p. 688

${ }^{17}$ Jackson P. D., Gunn, D. A., Meldrum P. I., and Flint R. C., 1994. 3D data processing and tomographic presentation of resistivity data. British Geological Survey Technical Report WN/94/20, 28 pp.

${ }^{18}$ Jackson P. D., Earl, S.J., and Reece, G.J., 2000. 3D resistivity inversion using 2D measurements of electric field. Geophysical Prospecting 49, 1-15.

${ }^{19}$ Singh, S. K. 1976. Fortran IV Program to compute apparent resistivity of a perfectly conducting sphere buried in a half-space. Computers and Geosciences $1: 241-245$. 


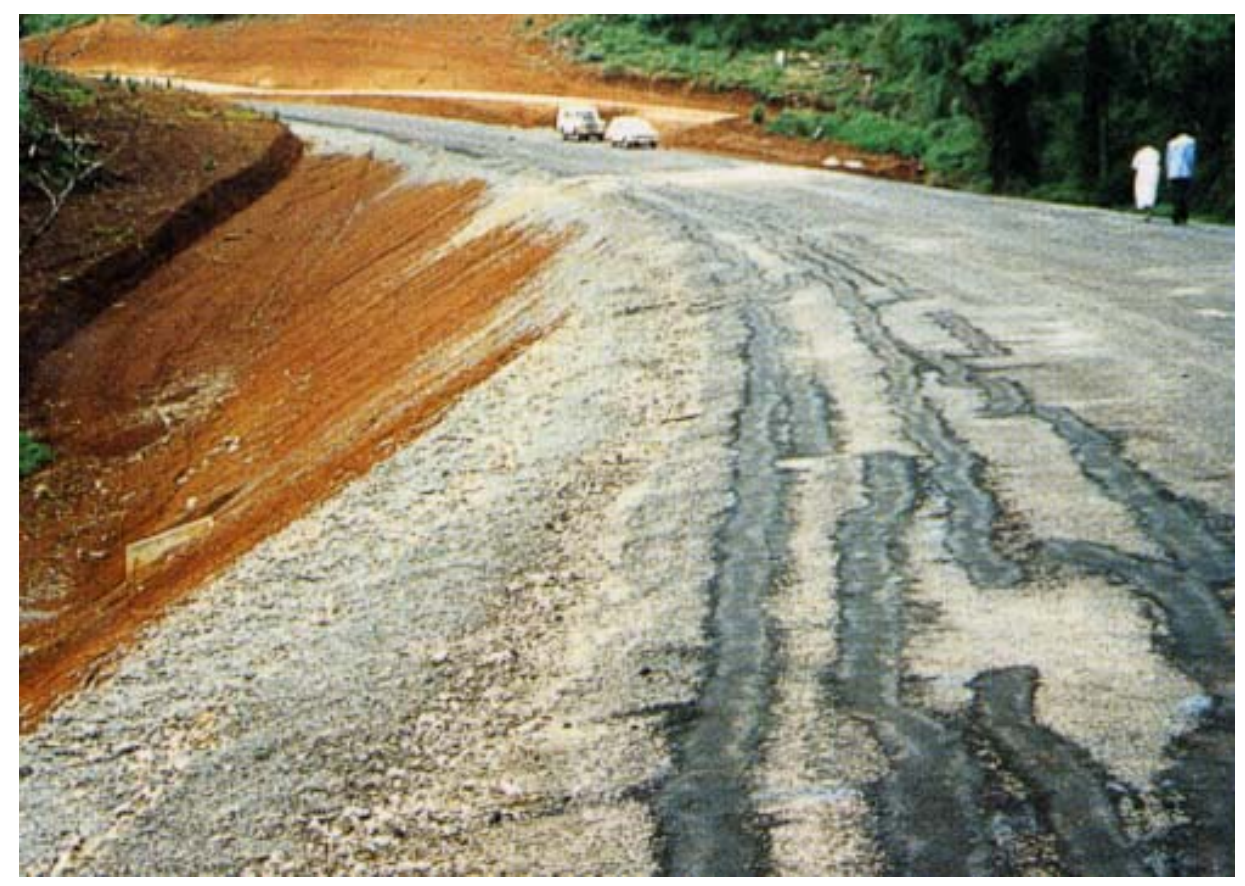

Figure 1. Cracking in a red soil road embankment in Kenya. Cracks up to six centimetres wide have been repaired with asphalt [10]

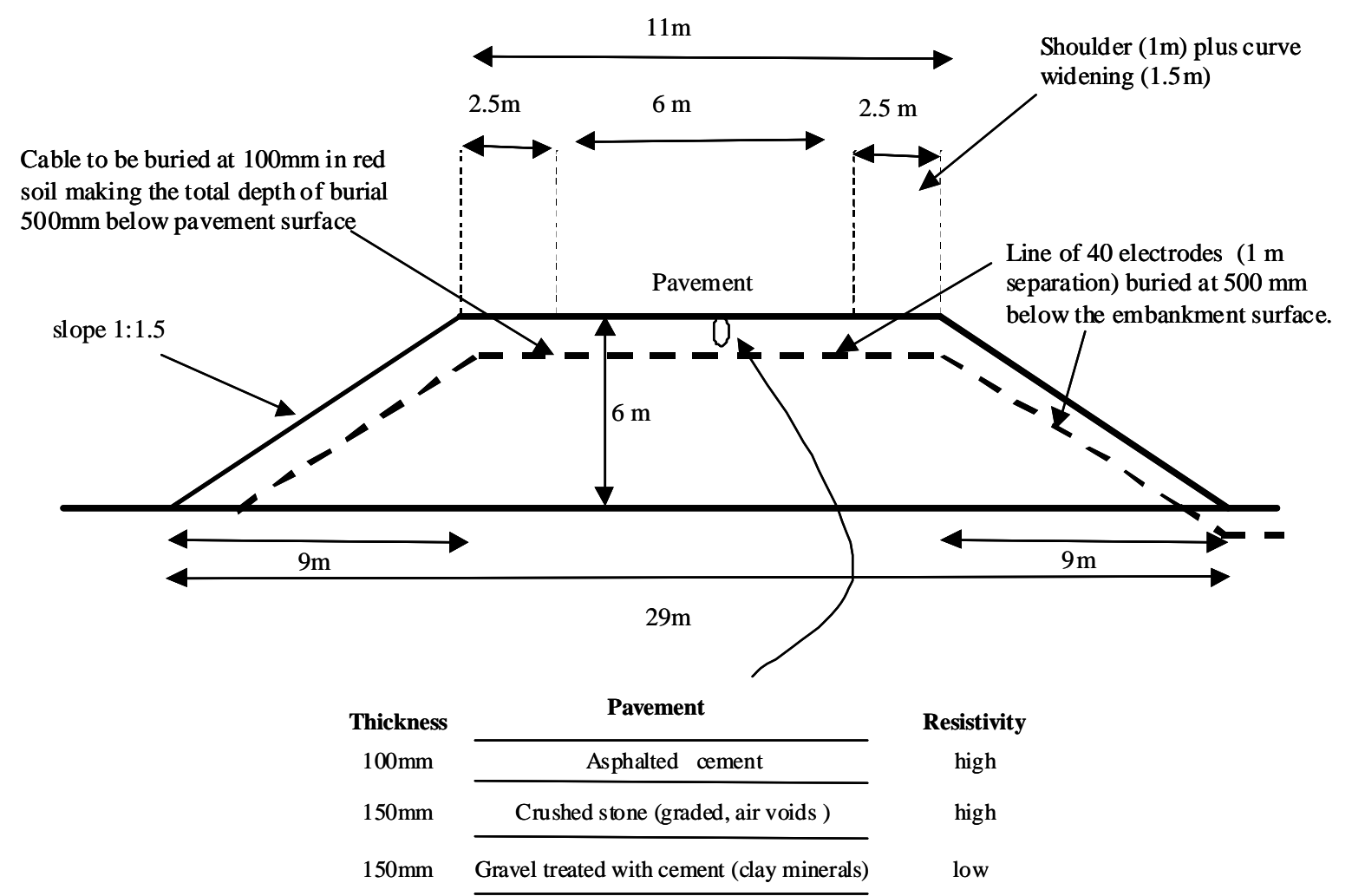

Fig. 2. Typical Red Soil Embankment Design (e.g. Molo Olenguruone K19 + 300) 


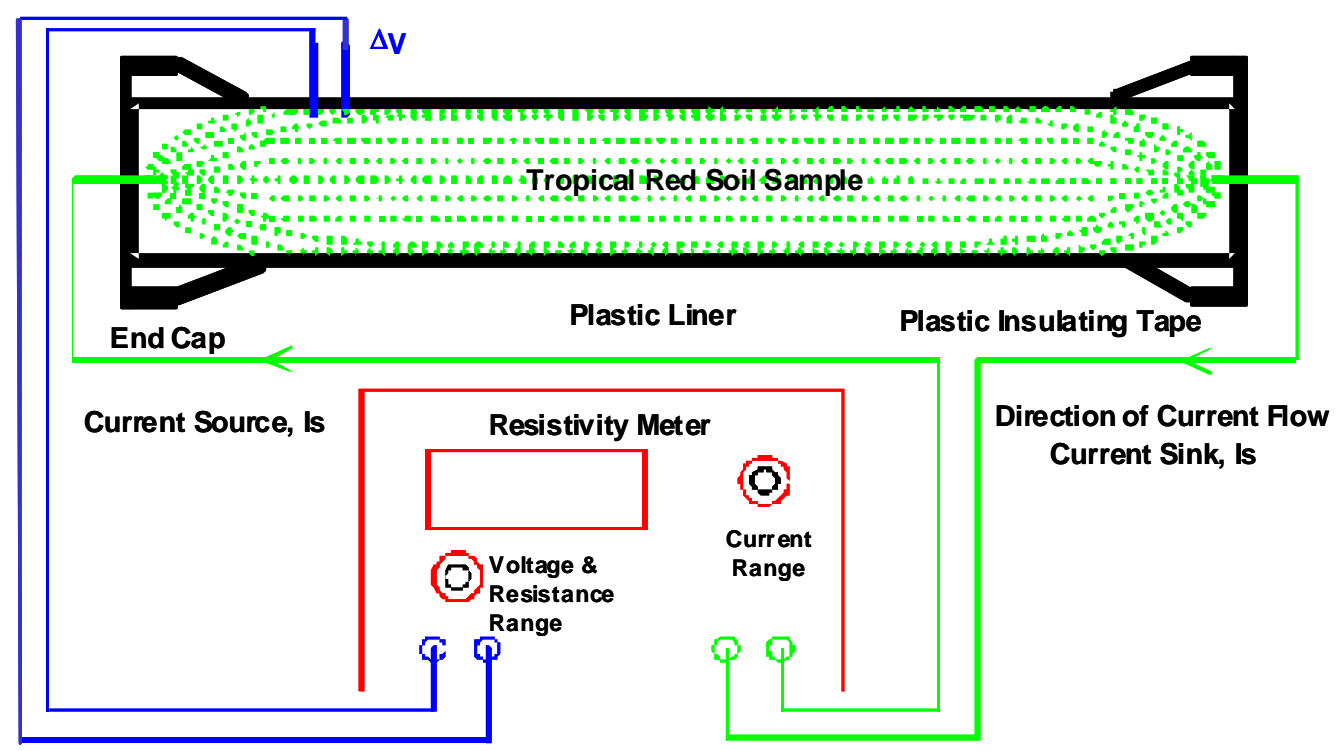

Fig. 3. Apparatus for measuring the resistivity of cores taken from embankments.

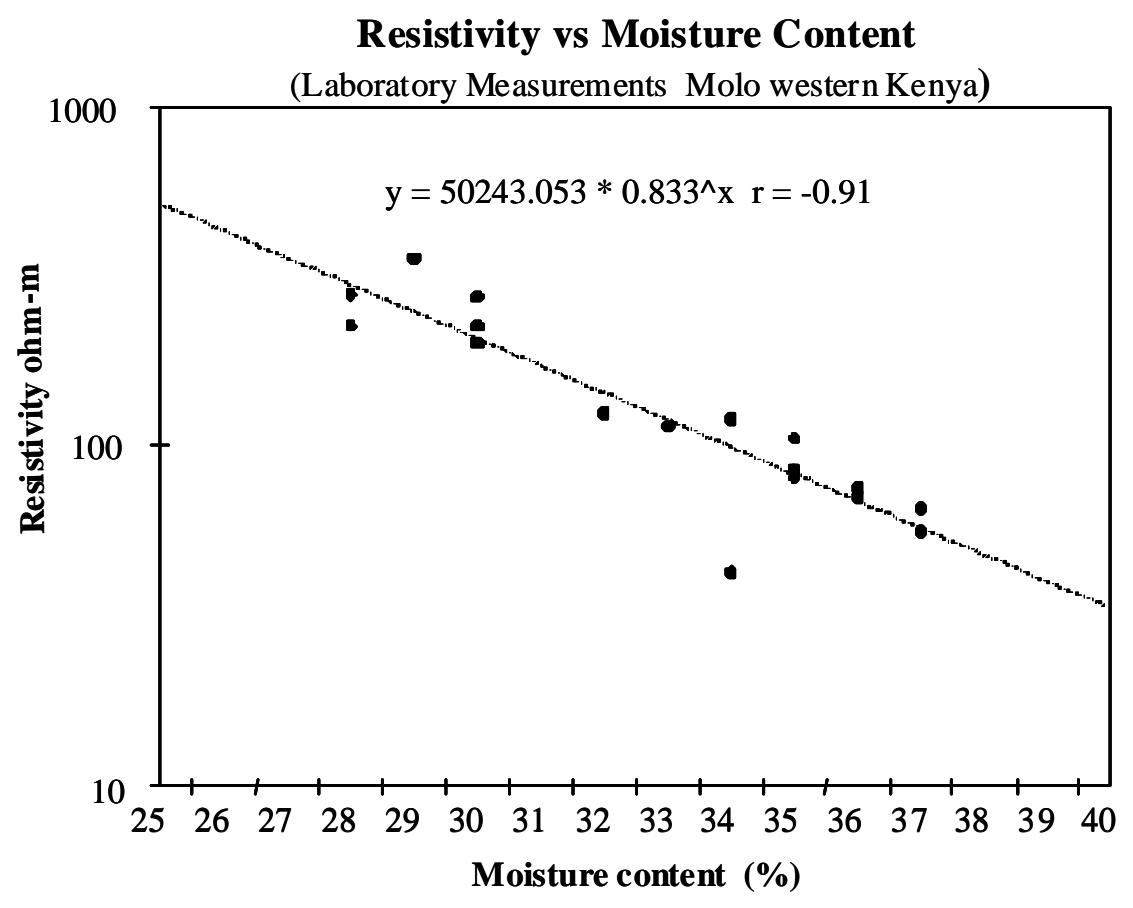

Fig. 4. An empirical relationship between resistivity and moisture content derived from laboratory measurements . 


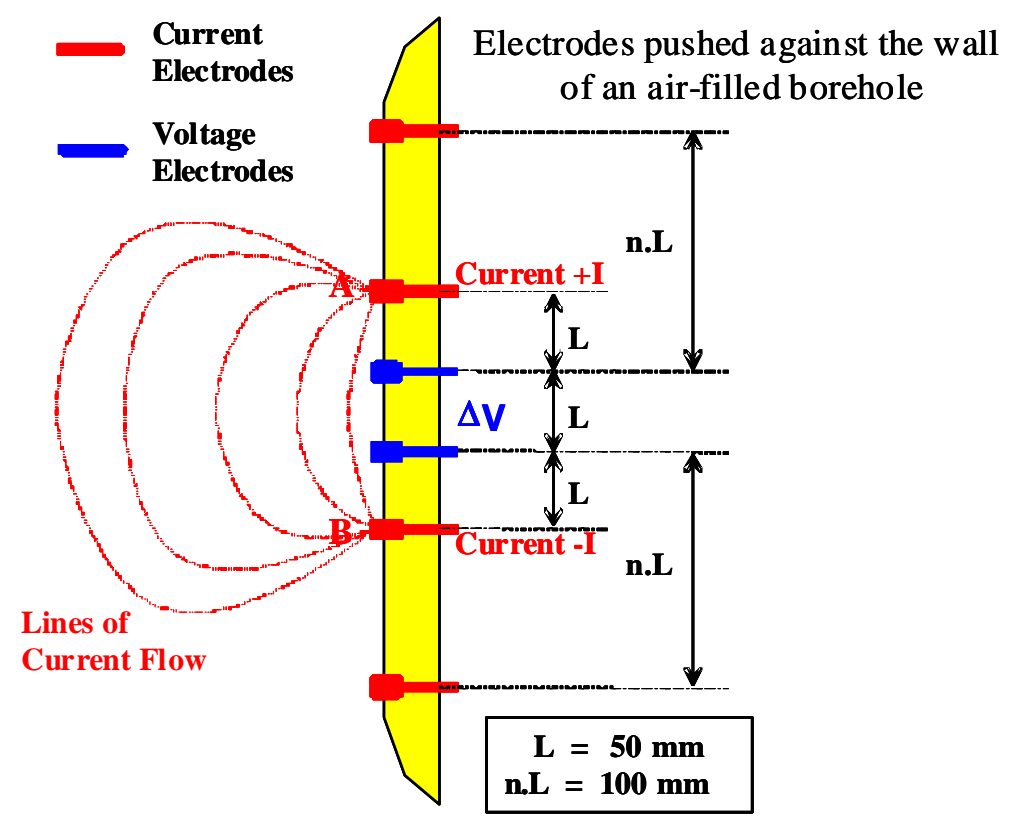

Fig. 5. Apparatus used to measure resistivity in open boreholes in embankment soils.

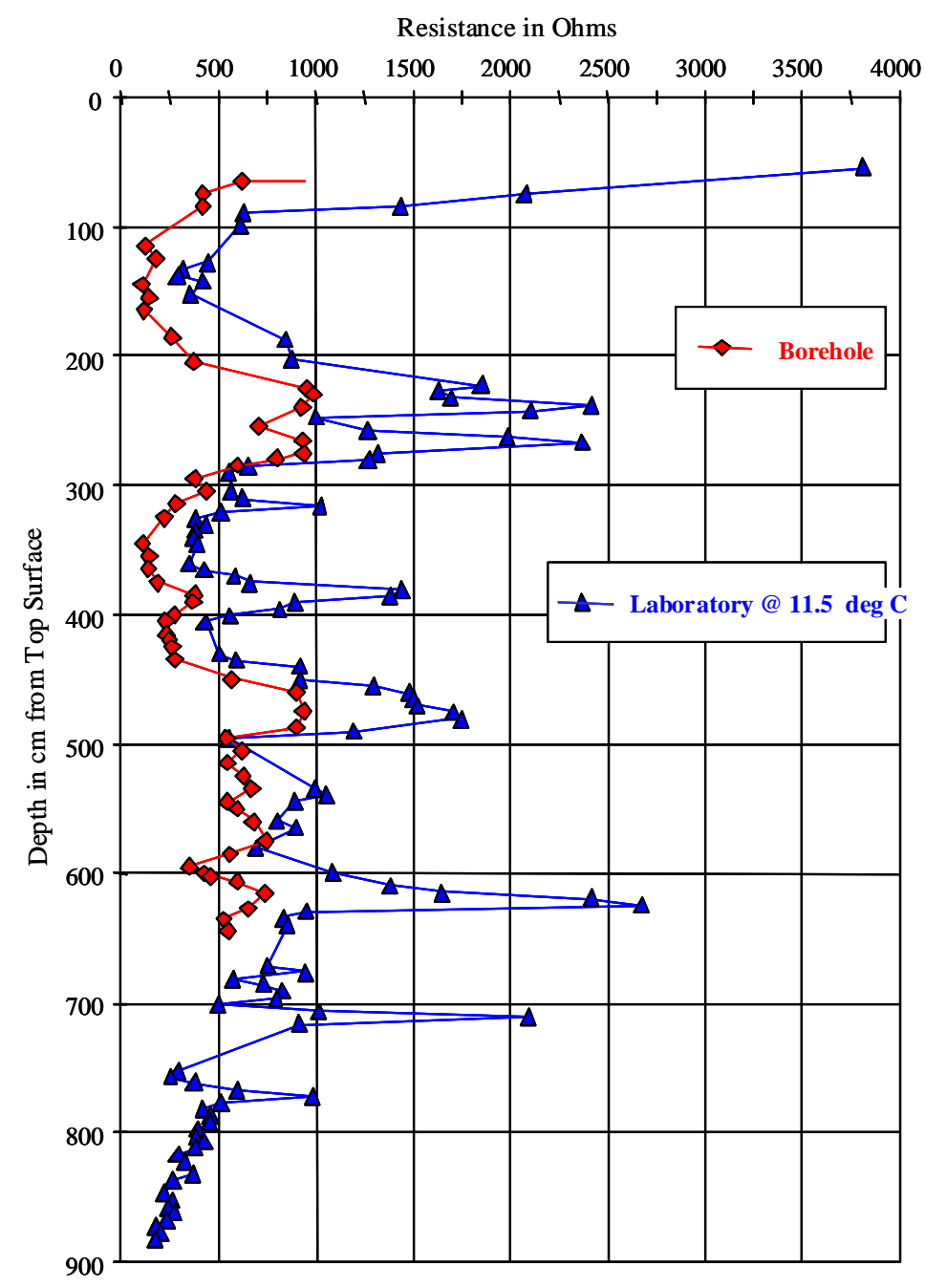

Fig. 6 A comparison of downhole and laboratory resistance measurements (Molo Olenguruone) 
The Barnes layer method adapted for the Schlumberger Array

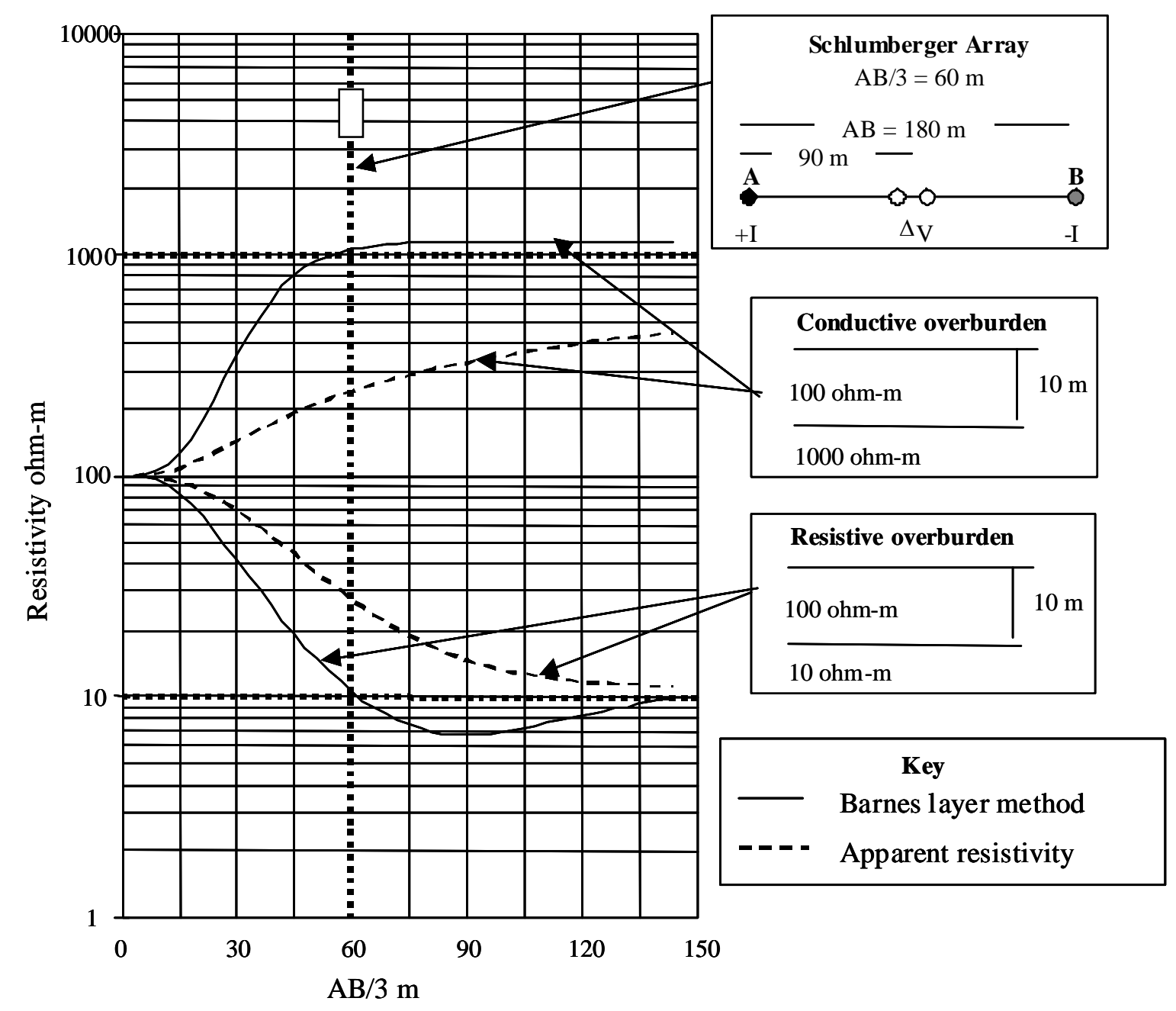

Fig. 7. A test of the Barnes layer method [16] adapted for the Schlumberger using a theoretical two-layer case at the surface of the earth, the theoretical values being calculated by the method of images [19].

Simulated pseudo-section of homogeneous embankment Numerical check of correction process
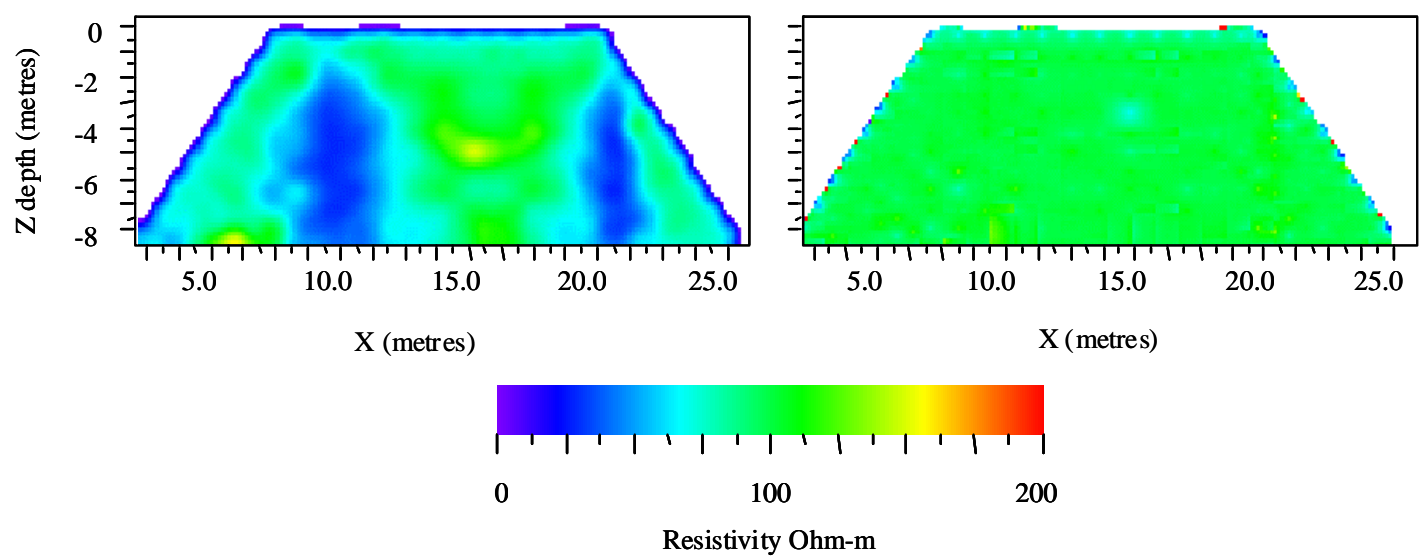

Fig. 8. Numerical, 3D simulation of a homogeneous embankment having a resistivity of $100 \mathrm{ohm}-\mathrm{m}$ (upper) plus its use to correct for topography (lower) 
Resistivity model used to simulate measurements

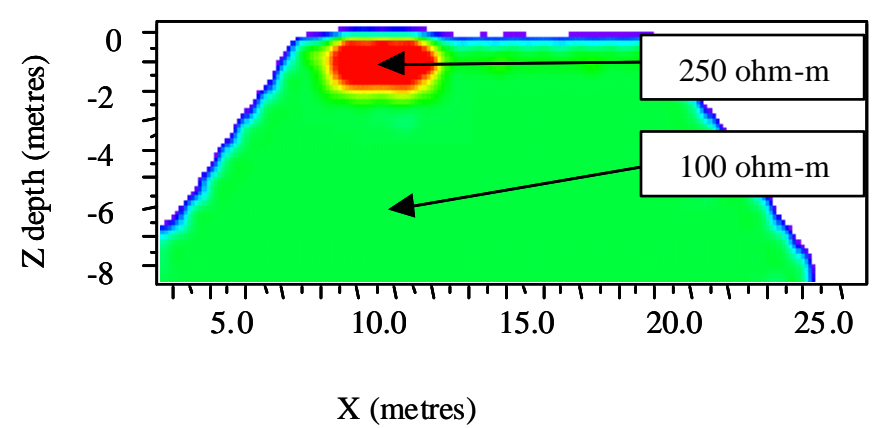

Resistivity pseudo section using measurements

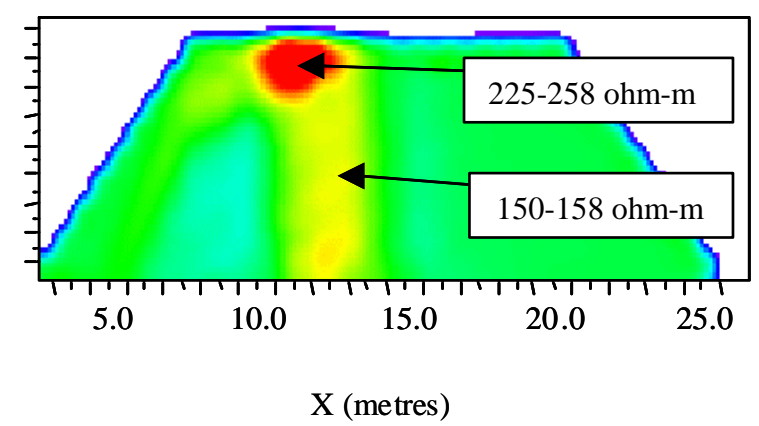

Fig. 9. Simulated resistivity pseud osection using topographical correction (Fig. 8) showing results that predicted the near-surface ground resistivity to within $10 \%$

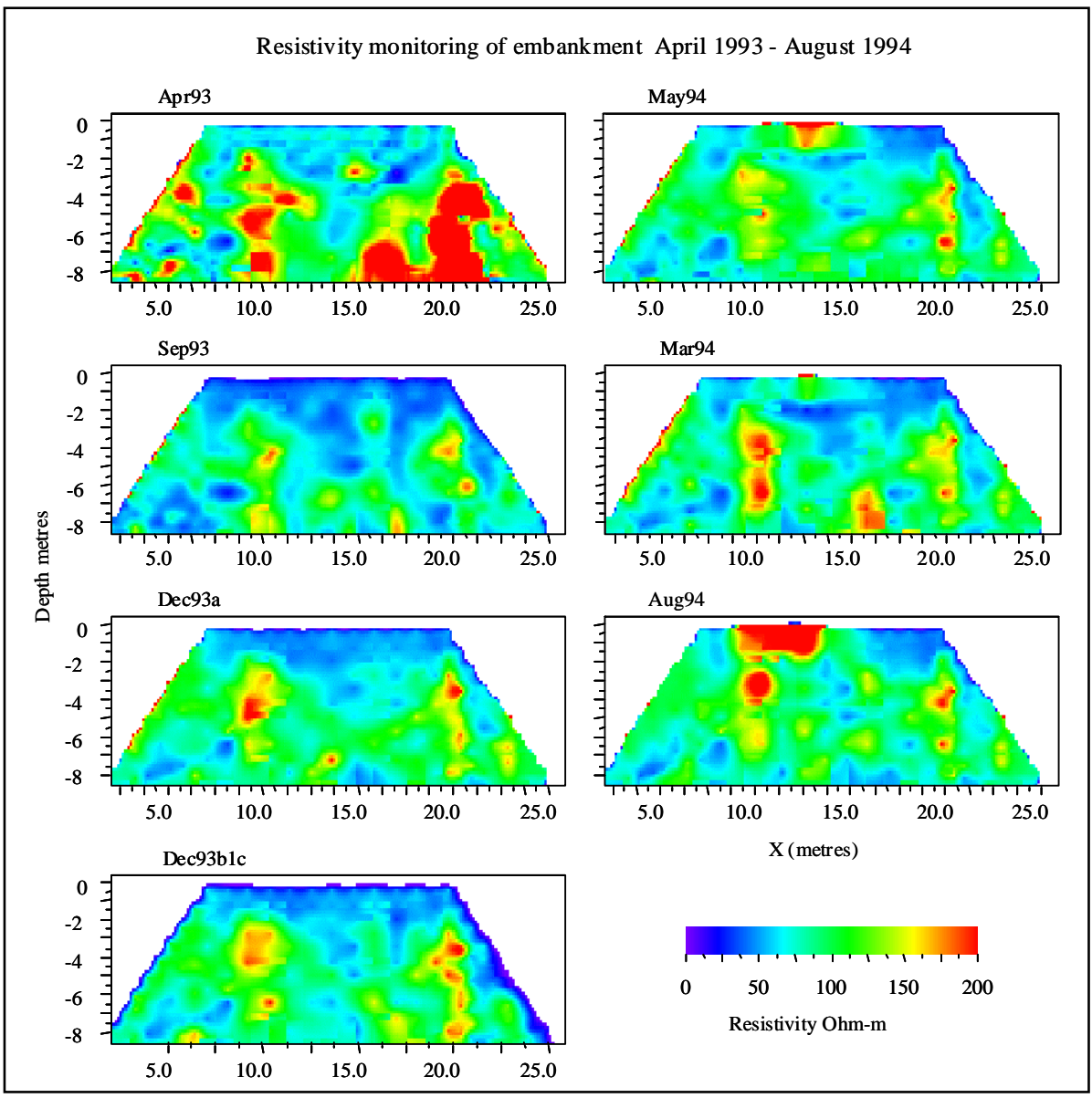

Fig. 10. Resistivity pseudo sections (Barnes' layer method) corrected for the crosssectional shape of the embankment at Molo western Kenya 
Moisture Content inferred from Resistivity Monitoring April 1993 - August 1994

Red Soil Road Embankment Molo Olenguruone K19 + 300
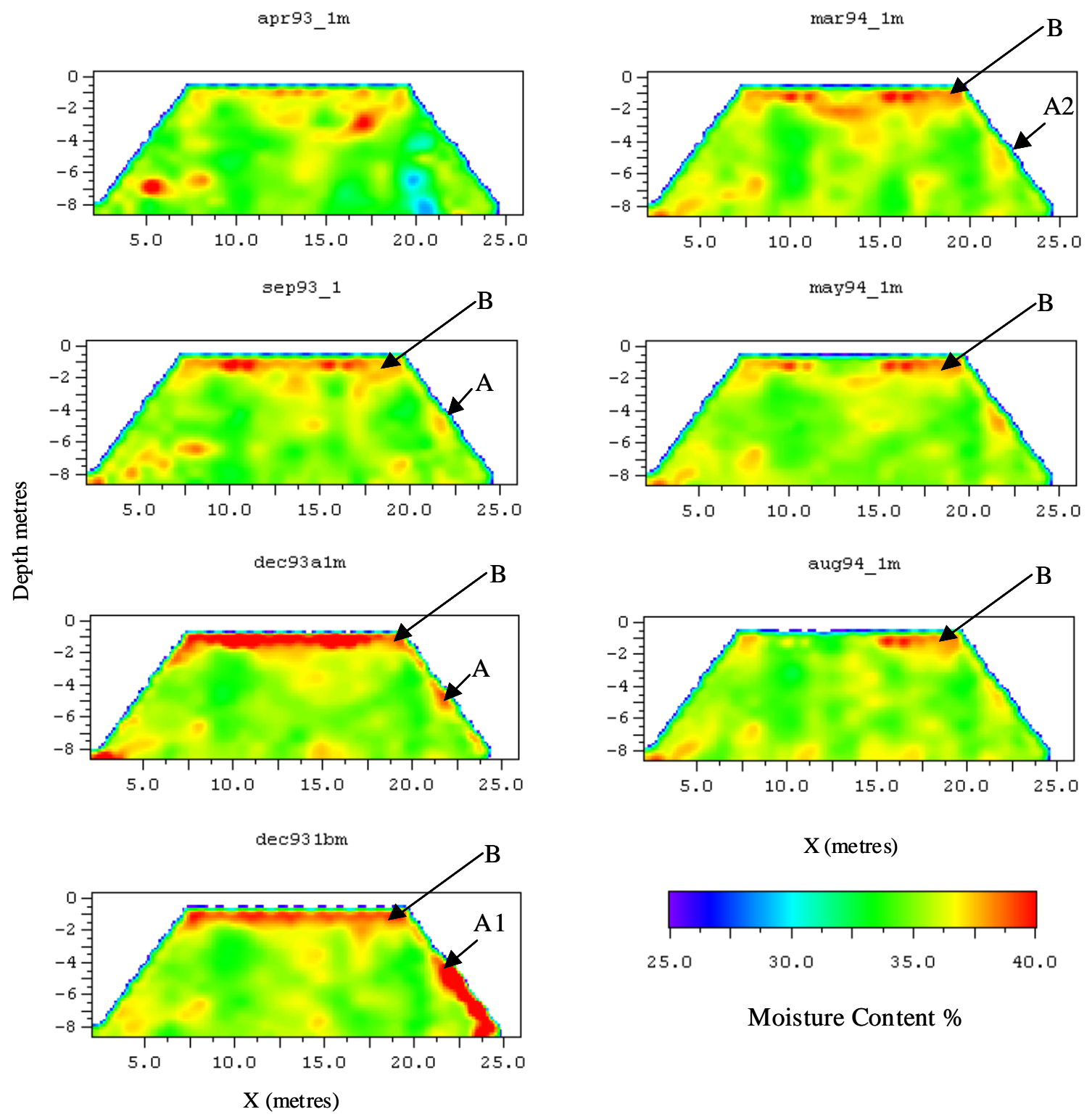

Moisture Content \%

Fig. 11. 2-D sections of moisture content, derived from the field resistivity measurements.

A - seepage horizon in embankment side slope 6 months after construction A1 - 3 months later at time of landslip

A2 - gravel drains installed to intercept seepage water and stabilise slope B - zone of persistently high moisture content in right shoulder 
Moisture monitoring using geophysics: a precursor to slope failure
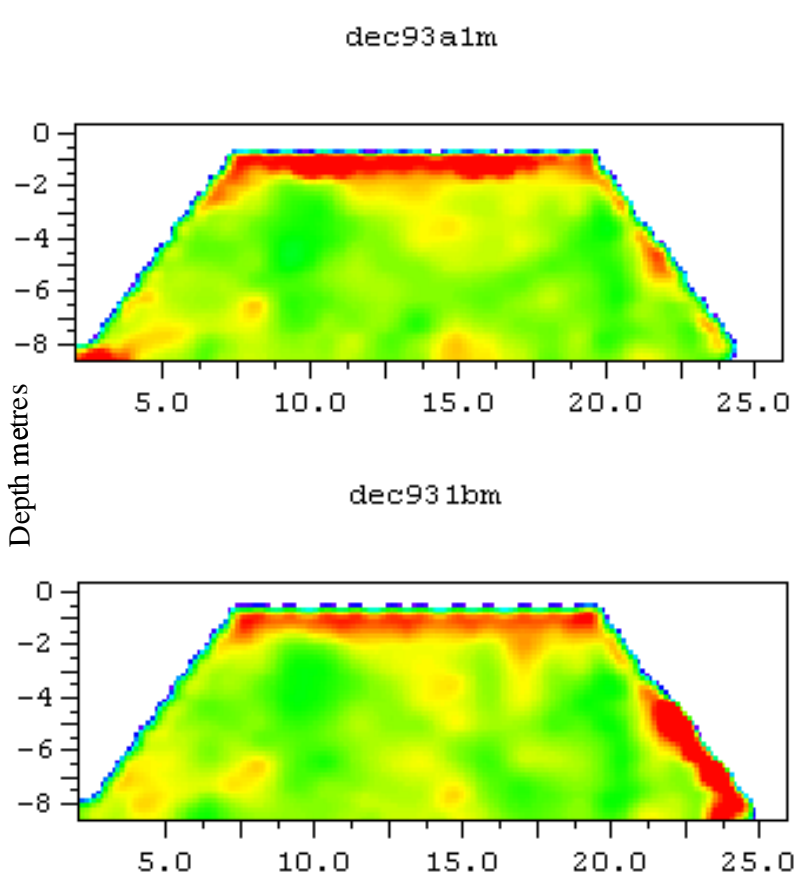

$\mathrm{X}$ (metres)

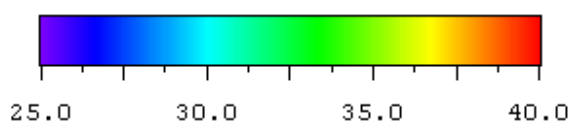

Moisture Content

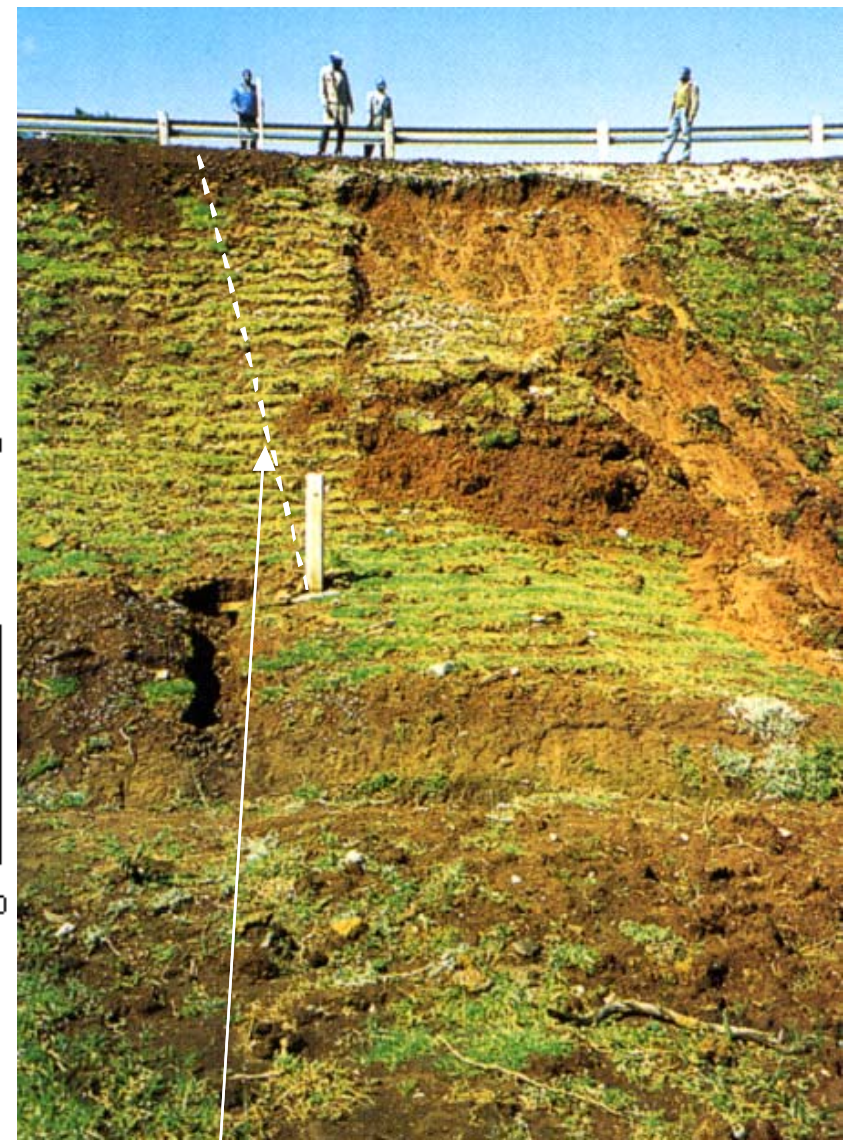

Line of buried electrodes

Fig. 12. 2-D sections of moisture content showing a dramatic increase in inferred moisture content (see Fig. 11) over a two week period in December 1993, prior to the slope failure depicted in the photograph 